\title{
The topology of cross-border exposures: beyond the minimal spanning tree approach
}

\author{
Alessandro Spelta * and Tanya Araújo ${ }^{\dagger}$ \\ University of Pavia, Italy \\ ISEG - Technical University of Lisbon (TULisbon) and \\ Research Unit on Complexity in Economics (UECE), Portugal
}

\begin{abstract}
The recent financial crisis has stressed the need to understand financial systems as networks of interdependent countries, where crossborder financial linkages play the fundamental role. It has also been emphasized that the relevance of these networks relies on the representation of changes follow-on the occurrence of stress events. Here, from series of interbank liabilities and claims over different time periods, we have developed networks of positions (net claims) between countries. Besides the Minimal Spanning Tree analysis of the time-constrained networks, a coefficient of residuality is defined to capture the structural evolution of the network of cross-border financial linkages. Because some structural changes seem to be related to the role that countries play in the financial context, networks of debtor and creditor countries are also developed. Empirical results allows to relate the network structure that emerges in the last years to the globally turbulent period that has characterized financial systems since the latest nineties. The residuality coefficient highlights an important modification acting in the financial linkages across countries in the period 1997-2011, and situates the recent financial crises as replica of a larger structural change going on since 1997.
\end{abstract}

*corresponding author: alessandro.spelta01@ateneopv.it

†tanya@iseg.utl.pt 


\section{Introduction}

Despite the conventional wisdom that national economies are interdependent there is less evidence on the contribution of economic crises to the reinforcement of cross-border financial interdependencies. The recent financial crisis has stressed the need to understand financial systems as networks of countries where cross-border financial linkages play the fundamental role. Furthermore, it has become clear that the relevance of these networks relies on the representation of changes follow-on the occurrence of stress events.

The adoption of an evolving network approach is recommended not only because of the proper emphasis on the financial interdependencies but also due to the possibility of describing how the structure of these interdependencies evolves in time. In so doing, we are able to address the role that an existing network structure plays in the spread of shocks and conversely, the effectiveness of stress events and their impact on the structure of the network.

In August 2007, the crisis of the subprime mortgage industry stormed the financial systems of several countries. As a response, hundreds of billions of dollars were injected by the authorities into the market. Nevertheless, this was not enough to avoid the second wave of a financial crisis.

Since the end of 2009, the down grading of Greek debt has been followed by several debt crises in the EU member states. As many of these countries cope with a decline in growth prospects and an increase in debts loads, the spread of the shocks seems to lead the EU to an unsustainable macro situation [1].

Deriving macro (global) situations from micro (local) scenarios has been a recurrent topic in economics. The way to link the macro and the micro levels hinges on graph theory, which has been recently introduced in economics to study formally the generation and stability of economic interactions among agents ([2] [3]). Even though basic geometric and topologic structures have already been used by Helpman and Krugman [4] to explain international trade relations, the knowledge on the complex structure of financial networks is far from being sufficient to realize the potential of the topological approaches.

Several authors have reported the opportuneness of describing financial linkages through a network approach. Some papers have favored the study of interdependencies between credit banks [5], or focused on the analysis of 
shocks storming the financial systems of several countries [6]. The topological properties of national interbank markets have also been studied by Soramaky and co-workers [7] as they analyzed the network topology of the interbank payments transferred between commercial banks over the Fedwire Funds Services [8]. In the same context, Fuijwara and collaborators explored the credit relationships between commercial banks and a set of Japanese companies [9].

The adoption of a network approach on empirical data has also been conducted in the characterization of the Italian [10] and the Austrian [11] interbank markets. More recently, Kubelec and collaborators [12] as well as Garratt and co-workers [13] used the Bank for International Settlements (BIS) consolidated banking statistics to develop cross-border banking networks. McGuire and co-workers [14] studied the international banking system while focussing in the cross-border financial trade. A similar approach was adopted by Minoiu and co-workers [15] in their study of global banking networks. For several extreme phenomena taking place at the global economic level, they found enough evidence of incoming instabilities in the network regime.

Starting from a geometrical setting we also followed a topological approach. Topological coefficients have been the object of growing attention ever since some network regimes were identified as the underlying structures of important phenomena found in many different fields. However, as most of these coefficients apply to graph structures that are connected and sparse, when analysing systems whose topological signature is a complete (fully-connected) network, there is a need to find out the corresponding representation of the system where sparseness replaces completeness in a suitable way. It has been often accomplished ([16], [17], [18 ] and [19]) through the construction of a Minimal Spanning Tree (MST).

In the present paper we have explored an equivalent approach to construct a sparse and connected network of financial linkages across countries. From time series of interbank liabilities and claims conducted through the international banking system, we have developed networks of countries' positions (net claims). The networks are built for the last 28 years and for two chronologically successive branches of 14 years.

In this context, besides the MST analysis of the cross-country networks, a coefficient of redundancy is defined to capture the structural changes occurring on the network along the last 28 years.

Because some structural changes seem to be related to the role that coun- 
tries play in the financial context, networks of debtor and creditor countries are also developed. Empirical results allows to relate the network structure that emerges in the last years to the globally turbulent period that has characterized financial systems since the latest nineties. The residuality coefficient highlights an important modification acting in the financial linkages in the period 1997-2011, and situates the turbulent period that has been characterizing the global financial system since the Summer 2007 as replica of a larger structural change going on for a decade. This occurs in such a systematic fashion that it may not be a statistical accident.

The paper is organized as follows: Section 2 briefly presents the set of empirical data we work with. Section 3 is targeted at presenting the method and the first results obtained from its application. The main contributions of the paper are presented in Sections 4 and 5: the coefficient of residuality and its application to the evaluation of the structural evolution of some specific networks as those that result from the identification of debtor and creditor countries. The paper ends with appropriate conclusions and outline of future work.

\section{The data}

The Bank for International Settlements (BIS) locational banking statistics (IBLR), including international claims and liabilities of reporting banks by country of residence and for the reporting area as a whole, provides a plentiful data set of aggregate cross-border exposures for a set of reporting and nonreporting countries all over the world.

The locational statistics were originally intended to complement monetary and credit aggregates, being consistent with both the national balances of payments and the systems of national accounts. For a subset of 57 reporting countries, the BIS publishes bank claims $(C)$ and liabilities $(L)$ on all other countries in a quarterly basis.

Our approach is applied to a subset of 24 reporting countries (see Table 1) ${ }^{1}$ and from this data source, bilateral exposures between each pair of countries are used to compute the position of each country vis-a-vis the rest of reporting countries.

\footnotetext{
${ }^{1}$ The first data collection date back to 1977 but a significant amount of statistics can be obtained only from the eighties. The statistics prior to 1983, includes just fifteen countries.
} 
The position $p_{i, t}$ of country $i$ in quarter $t$ is obtained subtracting liabilities $\left(L_{i, t}\right)$ from claims $\left(C_{i, t}\right)$

$$
p_{i, t}=C_{i, t}-L_{i, t}
$$

Thus, the position of each country corresponds to its net claims. From the countries' positions we are able to classify countries as creditor or debtor countries accordingly to the sign of $p_{i, t}$. If $p_{i, t}>0$ then country $i$ is a creditor but if it has a greater amount of liabilities than claims the country is a debtor, since $p_{i, t}<0$. Later in the paper (Section 5 ) we shall address that issue while applying the classification to further characterize the reporting countries.

\begin{tabular}{|c|c|}
\hline 1) AT: Austria & 13) IT: Italy \\
\hline 2) BS: Bahamas & 14) JP: Japan \\
\hline 3) BH: Bahrain & 15) LU: Luxemburg \\
\hline 4) BE: Belgium & 16) NL: Netherlands \\
\hline 5) CA: Canada & 17) AN: Netherlands Antilles \\
\hline 6) KY: Cayman Islands & 18) NO: Norway \\
\hline 7) DK: Denmanrk & 19) SG: Singapore \\
\hline 8) FI: Finland & 20) ES: Spain \\
\hline 9) FR: France & 21) SE: Sweden \\
\hline 10) DE: Germany & 22) CH: Switzerland \\
\hline 11)HK: Hong Kong & 23) GB: United Kingdom \\
\hline 12) IE: Ireland & 24) US: United States \\
\hline
\end{tabular}

Table 1: Reporting Countries

Since the BIS locational banking statistics capture the net flows of financial capital between any two countries channeled through the banking system [20], this data set is an appropriate source to the empirical study of temporal patterns arising from financial linkages across countries.

\section{The Method}

Cross-correlation based distances, as applied in reference [16] to the study of stock market structure have been used in the analysis and reconstruction of geometric spaces in many different fields. The quantity 


$$
d_{k l}=\sqrt{2\left(1-C_{k l}\right)}
$$

where $C_{k l}$ is the correlation coefficient of two time series $\vec{s}(k)$ and $\vec{s}(l)$ computed along a given time window

$$
C_{k l}=\frac{\langle\vec{s}(k) \vec{s}(l)\rangle-\langle\vec{s}(k)\rangle\langle\vec{s}(l)\rangle}{\sqrt{\left(\left\langle\vec{s}^{2}(k)\right\rangle-\langle\vec{s}(k)\rangle^{2}\right)\left(\left\langle\vec{s}^{2}(l)\right\rangle-\langle\vec{s}(l)\rangle^{2}\right)}}
$$

has been shown [17] to satisfy all the metric axioms.

\subsection{The Metric}

Using the BIS time series with claims and liabilities and after computing the quarterly based position of each country $(\vec{p}(i))$ vis-a-vis the other reporting countries, we define a normalized vector

$$
\vec{\rho}(i)=\frac{\vec{p}(i)-\langle\vec{p}(i)\rangle}{\sqrt{n\left(\left\langle\vec{p}^{2}(i)\right\rangle-\langle\vec{p}(i)\rangle^{2}\right)}}
$$

$n$ being the number of components (number of time labels) in the vectors $\vec{p}(i)$. With this vector one defines the distance between the countries $i$ and $j$ by the Euclidean distance of the normalized vectors,

$$
d_{i j}=\sqrt{2\left(1-C_{i j}\right)}=\|\vec{\rho}(k)-\vec{\rho}(l)\|
$$

where $C_{i j}$ is the correlation coefficient of the positions $\vec{p}(i)$ and $\vec{p}(j)$, respectively of countries $i$ and $j$ computed along a time window of $n$ (quarterly) observations.

Having computed the matrix of distances $(D)$ for the set of 24 reporting countries $(N=24)$ on a time interval of 110 quarters $(n=110)$, we are able to provide three pictorial representations of this set, as Figure 1 shows.

Although the first plot presented in Figure 1(a) graphically informs about the distribution of the distances between countries, the fully-connected nature of this set does not help to find out whether there is a dominant pattern taking place. Therefore, the first step should be targeted at obtaining a sparse representation of the set of distances, with the degree of sparseness generated by the set of distances itself, instead of an a priori specification. At the 
same time, when looking for a suitable degree of sparseness, one must avoid disconnected graphs. To this end, we construct the corresponding MST.

\subsection{From complete networks to sparse graphs: the minimal spanning tree approach}

From the $N x N$ distance matrix $D$, a hierarchical clustering is then performed using the nearest neighbor method. Initially $N$ clusters corresponding to the $N$ countries are considered. Then, at each step, two clusters $c_{i}$ and $c_{j}$ are clumped into a single cluster if

$$
d\left\{c_{i}, c_{j}\right\}=\min \left\{d\left\{c_{i}, c_{j}\right\}\right\}
$$

with the distance between clusters being defined by

$$
d\left\{c_{i}, c_{j}\right\}=\min \left\{d_{p q}\right\} \text { with } p \in c_{i} \text { and } q \in c_{j}
$$

This process is continued until there is a single cluster. This clustering process is also known as the single link method, being the method by which one obtains the minimal spanning tree (MST) of a graph.

In a connected graph, the MST is a tree of $N-1$ edges that minimizes the sum of the edge distances. In a network with $N$ nodes, the hierarchical clustering process takes $N-1$ steps to be completed, and uses, at each step, a particular distance $d_{i, j} \in D$ to clump two clusters into a single one.

Let $C=\left\{d_{q}\right\}, q=1, \ldots, N-1$, be the set of distances $d_{i, j} \in D$ used at each step of the clustering, and $L=\max \left\{d_{q}\right\}$. It follows that $L=d_{N-1}$.

After computing the threshold distance value $(L)$ we are able to define a representation of $D$ with sparseness replacing fully-connectivity in a suitable way.

The result of the hierarchical clustering process leading to the MST is usually described by means of a dendrogram. During this process, a unique color is assigned to each group of nodes within the dendrogram whose linkage is less than $T$ times the value of the threshold distance $L\left(\max \left\{d_{q}\right\}\right)$. In the dendrograms presented here, $T$ is set to 0.7 .

The dendrogram obtained from the matrix of distances presented in Figure 1 (a) is shown in the second plot (b) of Figure 1. There, three clusters can be observed. The first cluster (colored blue) comprises the countries 
FI(8), SE(21), DK(7), NO(18), NL(16), GB(23) and IT(13). The second cluster (black) encompasses countries $\mathrm{KY}(6), \mathrm{FI}(8), \mathrm{CH}(22), \mathrm{AN}(17)$, while

the third (red) comprises countries FR(9), DE(10), BE(4), LU(15), AT(1), $\mathrm{CA}(5), \mathrm{HK}(11)$ and JP(14). From this dendrogram we observe that the first two clusters seem to be closely related, while a distinct situation characterizes the third one. Countries BS (2) and $\mathrm{BH}(3)$ occupy quite distinct positions on the tree, being the last ones to be connected in the hierarchical clustering process. The third plot (c) in Figure 1 shows a network representation of the corresponding MST. It is worth noting that two countries are close (short-distant) on the MST whenever the evolution of their net claims is correlated. Conversely, poorly correlated countries use to be those occupying distant positions on the MST.

Plot (c) in Figure 1 highlights the role of Norway, which is connected to several countries, displaying high centrality. The same happens to Austria in the upper branch of this graph.

When a geographical perspective is taken, the first cluster may be identified as the one representing the European peripherical countries, including the northest countries $\mathrm{FI}(8), \mathrm{SE}(21), \mathrm{DK}(7), \mathrm{NO}(18), \mathrm{NL}(16), \mathrm{GB}(23)$ and two Mediterranean ones (IT(13) and ES(20)). The second cluster brings together the central European countries FR(9), AT(1), DE(10), BE(4), LU(15) but also includes the non-EU countries JP(14), CA(5) and HK(11). Such a geographically driven trend is in accordance with the recent study presented in reference [12] on the geographical composition of countries' external positions and its increasing trend since the mid-1990's. Accordingly to this reference, this increasing trend in the countries' positions has been specially pronounced among industrial countries, where financial integrations has overstepped trade integration.

Besides the geographically-oriented nature, the MST representation of the 24 reporting countries does not seems to reveal other relevant concerns.

\subsection{Looking at chronologically successive periods}

To have a comparative idea on the structure inferred from the BIS data, we have divided the data in two chronologically successive batches - from 1983 to 1997 and from 1997 to 2011 - and performed the same operations.

The three plots in Figure 2 show the distance matrix, the dendrogram and the network representation of the MST obtained for the period 1983-1997. 


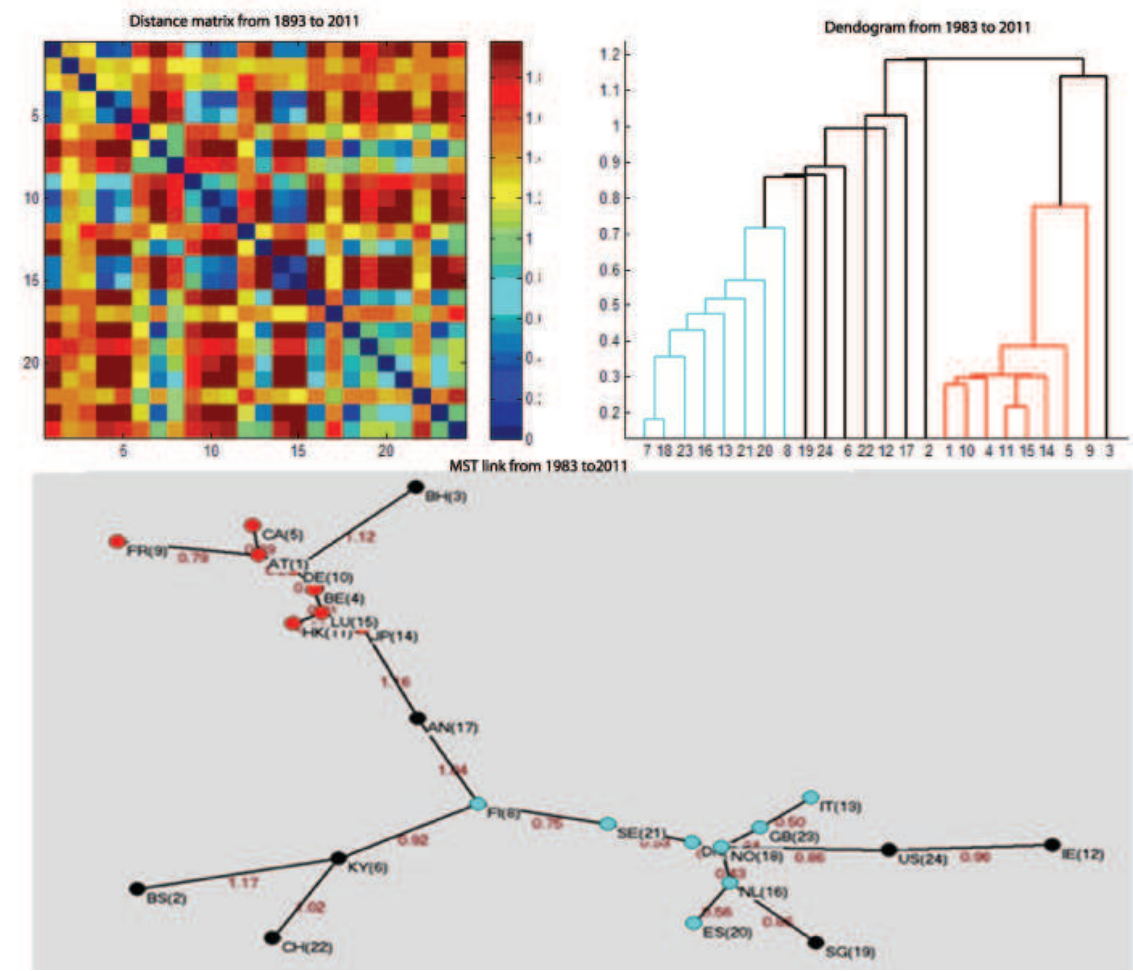

Figure 1: From 1983 to 2011 (a) the Matrix of Distances (b) the Dendrogram (c) the MST links

The first cluster (green) is the biggest one and encompasses countries $\mathrm{AT}(1), \mathrm{GB}(23), \mathrm{SE}(21), \mathrm{CA}(5), \mathrm{FR}(9), \mathrm{ES}(20), \mathrm{FI}(8), \mathrm{IE}(12), \mathrm{NO}(18), \mathrm{BE}(4)$, $\mathrm{DK}(7), \mathrm{JP}(14), \mathrm{AN}(17), \mathrm{LU}(15), \mathrm{CH}(22)$ and $\mathrm{SG}(19)$. The second (blue), being highly correlated with the first, is comprised of countries $\mathrm{HK}(11), \mathrm{DE}(10)$ and $\mathrm{NL}(16)$. The third cluster (red) includes countries $\operatorname{IT}(13), \mathrm{BS}(2), \mathrm{BH}(3)$ and US(24). Country KY(6) is the latest one to be connected on the MST. It is worth noting that the need to include this country in the MST structure introduces an increase in the threshold distance value $(L)$ of more than $20 \%$.

Now clusters are no longer geographically-oriented and the dendrogram seems to be characterized by greater uniformity in the distances between countries. These distances are shortened, leading the whole set of countries 


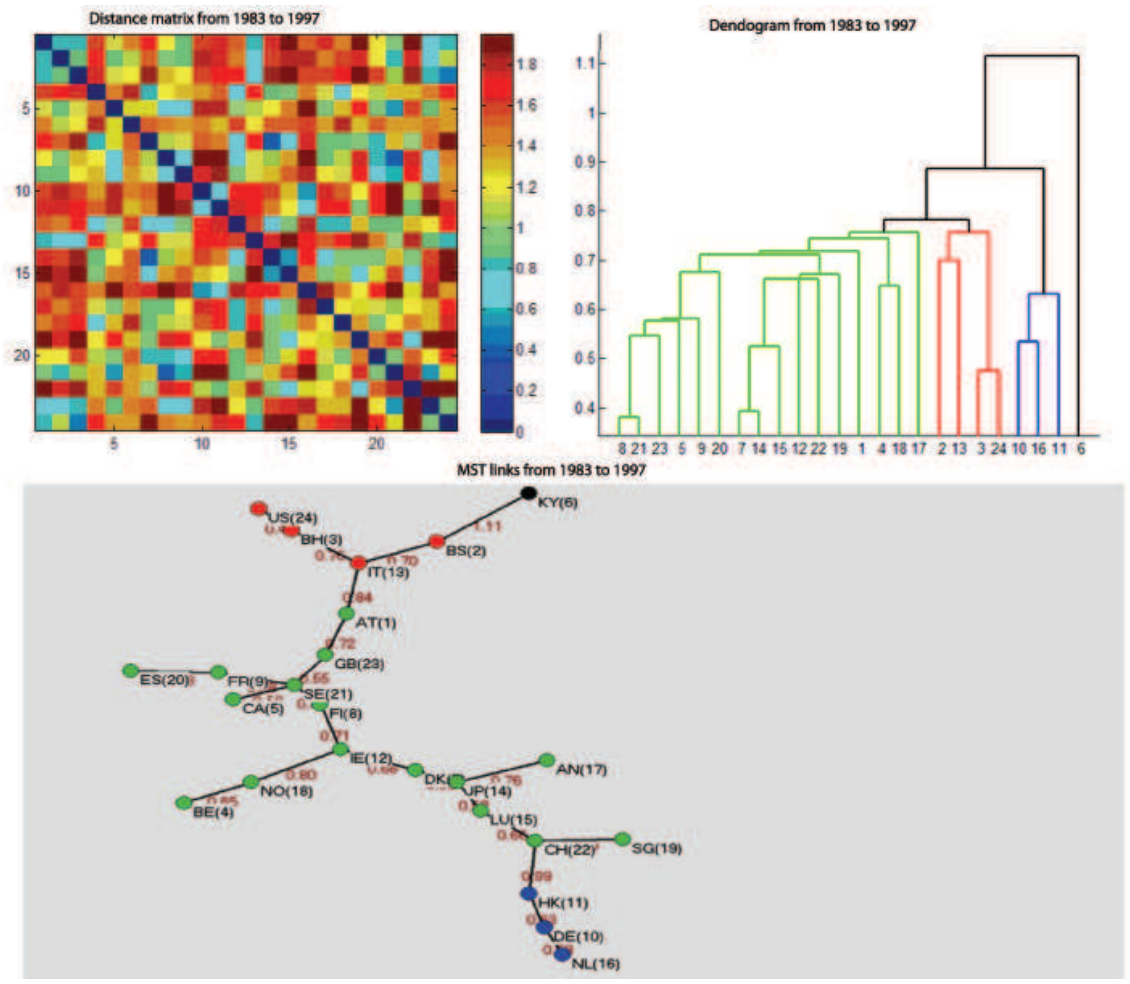

Figure 2: From 1983 to 1997 (a) the Matrix of Distances (b) the Dendrogram (c) the MST links

to apparently converge to a single cluster.

The three plots in Figure 3 show the distance matrix, the dendrogram and the MST obtained for the period 1997-2011, where structural changes have led to important modifications in the corresponding MST, mostly when compared with the results obtained for the period 1983-1997.

Three clusters are present, the first one (green) includes countries $\mathrm{KY}(6)$, FI(8), SE(21), DK(7), NO(18), IT(13), ES(20), GB(23) and NL(16). The second (blue) is formed by only two countries $\operatorname{IE}(12)$ and US(24), while the third (red) encompasses countries CA(5), AT(1), JP(14), DE(10), BE(4), FR(9), LU(15) and HK(11). The corresponding MST informs that the two main clusters are linked together by the two farthest countries $(\mathrm{BH}(3)$ and 


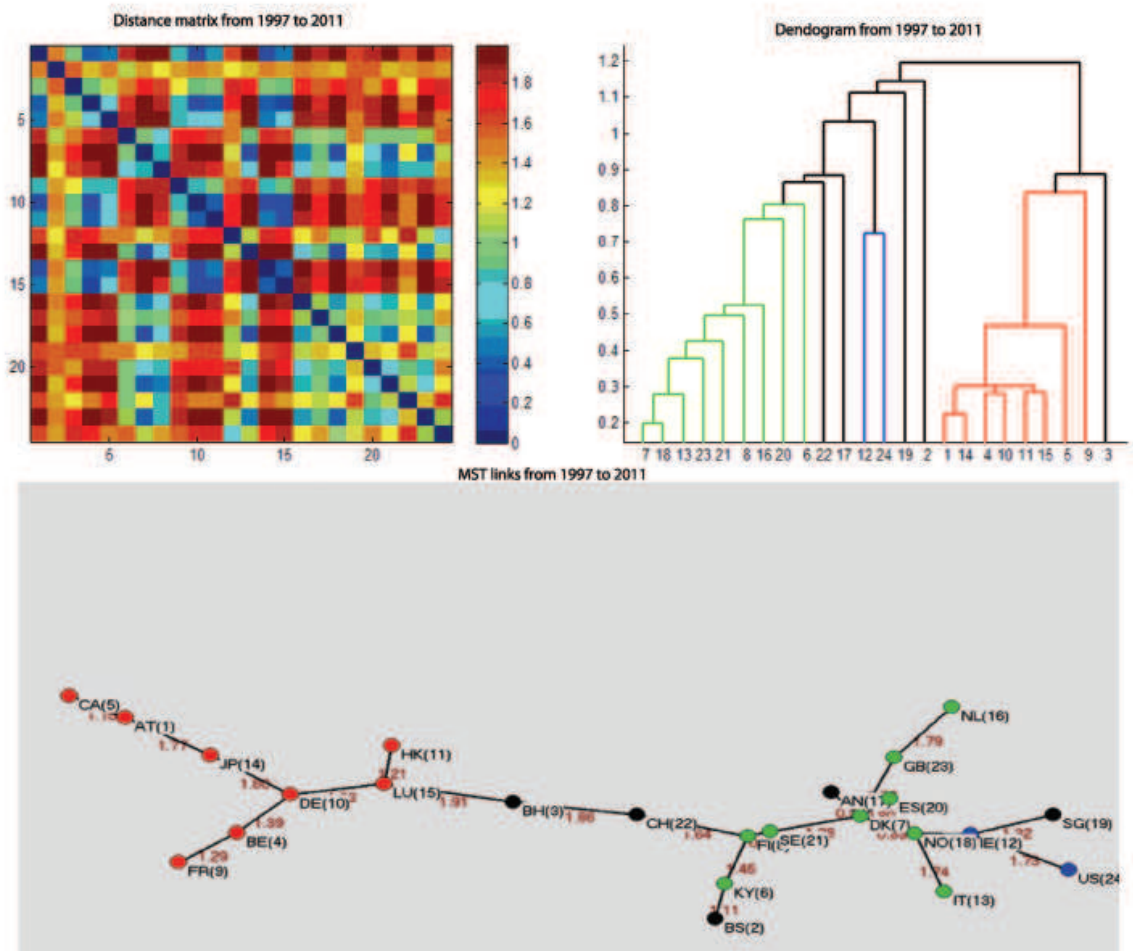

Figure 3: From 1997 to 2011 (a) the Matrix of Distances (b) the Dendrogram (c) the MST links

$\mathrm{CH}(22)$ ) among the whole set. The emergence of long distant links (low intensity connections) playing such a central role use to be associated to less robust network structures, whenever robustness is defined as propensity to connectedness preservation.

Now, Denmanrk (DK(7)) and Germany (DE(10)) seem to be the countries with greater centrality. The threshold distance value increases in this last period, highlighting a higher degree of separation between the two largest clusters.

It shall be noticed that these first results suggest that some structural changes taking place in this last period are better observed when countries are classified accordingly their debtor or creditor roles. In so doing, the MST 
representation in Figure 3 shows a remarkable concentration of heavily indebted countries in the first cluster, leaving the third cluster to be comprised of countries that play the creditor role.

Structural changes in this period were certainly driven by the occurrence of some stress events as the Asian (1997, 2nd Black Monday), Russian (1998) and Japanese (1999) crises in the latest nineties. Instead of a geographicallyoriented structure, the network emerging in this last period seems to be driven by the debtor/creditor roles.

\section{Beyond the MST approach}

In the last section, the construction of a MST allowed for the definition of networks where sparseness replaces fully-connectivity in a suitable way. However this construction neglects part of the information contained in the distance matrix, since it only takes the $N-1$ distances that are considered in the hierarchical clustering process.

In order to avoid this loss of information we define the projected graph $B$ (with $N$ vertices being the network nodes) by setting $b_{i, j}=d_{i, j}$ if $d_{i, j}<L$ and $b_{i, j}=0$ if $d_{i, j}>L$. As usual, null $\operatorname{arcs}$ of $B$ are those for which $b_{i, j}=0$. Here we want to consider two nodes $i$ and $j$ to be connected if $d_{i, j}<L$.

Let $A$ be the boolean graph associated with $B$, where each element $a_{i, j}$ is the number of edges of $B$ that join the vertices $i$ and $j$ and, since $B$ is a simple graph, $a \in\{0,1\}$.

The three plots in Figure 4 show the boolean graphs $(A)$ obtained for the three periods: 1983-2011, 1983-1997, 1997-2011. They were obtained by:

1. Taking the matrix of distances $(D)$ of each period (presented in the first plots of Figures 1,2 and 3).

2. Applying the hierarchical clustering process to obtain the distance $d_{N-1} \in C$ used in the last step of the hierarchical clustering process.

3. Building the corresponding boolean graph $(A)$ where unit arcs $\left(d_{i j} \leq\right.$ $\left.d_{N-1}\right)$ are represented as black patches and null arcs $\left(d_{i j}>d_{N-1}\right)$ correspond to white ones. 

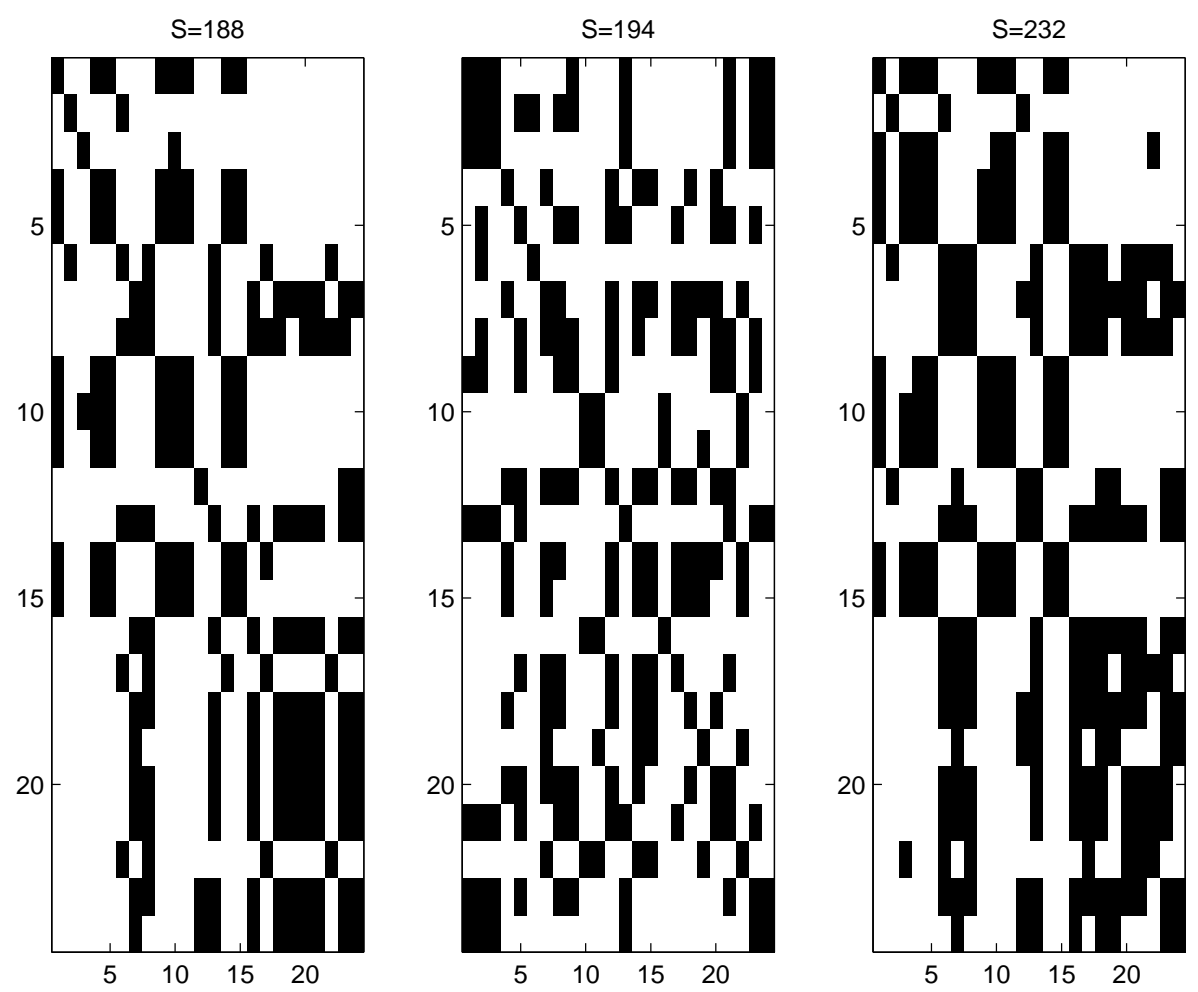

Figure 4: The boolean graphs (a) 1983-2011 (b) 1983-1997 (c) 1997-2011

Having defined the boolean representation associated to each time period, we are also interested in defining $C^{*}=\left\{d_{l}\right\}, l=1, \ldots, M$ as the set of distances in $D$ whose values are less or equal to $L$ and computing $S=M-(N-1)$.

Clearly $S>0$ is the number of redundant elements in $C^{*}$, that is, the number of distances $d_{i, j}$ that, although being smaller than $L$, need not be considered in the hierarchical clustering process.

In a connected graph, $S$ provides the cardinality of the cycle basis of the graph, or its cyclomatic number. Being a cycle basis of a graph defined by the set of its elementary cycles that taken together yield the entire graph. In this context, cycles and trees (i.e., connected graphs without cycles) may or not appear in the resulting network structures [21]. The clustered networks have a high coordination number while in the opposite case the networks 
approach a tree-like structure and, consequently, low clustering.

Computing $S$ for the three time periods 1983-2011, 1983-1997 and 19972011 yields respectively 188, 194 and 232. The value of $S$ obtained for the later period shows an increase in the number of redundant links. Not surprisingly, increasing cluster use to be a consequence of disturbed periods being the topological correlate of the occurrence of stress events.

It has been empirically observed that both during economic expansion and normal periods, financial markets tend toward randomness whereas in the disturbed periods its structure is reinforced in the topological sense, as revealed by the clustering measures (a detailed discussion on the role of clustering in financial crises can be found in references [22], [23] and [24]). The number of redundant elements that characterize the distinct time periods provides enough evidence on the structural changes taking place on the network structure. They are due to the emergence of high correlated positions (synchronization) in the network of countries.

To better capture structural changes we also define the residuality coefficient

$$
R=\frac{\sum_{d_{i, j}>L} d_{i, j}^{-1}}{\sum_{d_{i, j} \leq L} d_{i, j}^{-1}}
$$

where $L$ is the highest threshold distance value that insures connectivity of the whole network in the hierarchical clustering process.

Residuality relates the relative strengths of the connections above and below the threshold distance value.

Figure 5 shows the values of $R$ along the 28 years and with a time window of 56 quarters (14 years). At each quarter $(t) R$ is computed from the distances measured along a moving window of length 56 . The choice of such a wide window ensures statistical robustness and allows for capturing the main differences in the behavior of $R$ when the latest nineties start to be taken into account. Indeed, Figure 5 shows that the lowest values of $R$ correspond to the 14 years starting at the last quarter of 1993 and that, after the end of $1997, R$ does not return to the previous configuration.

The decrease of the residuality coefficient observed in Figure 5 seems to be twofold: it happens because the connection strengths $d_{i j}^{-1}$ above $\frac{1}{L}$ tend to be stronger than those that remain below the threshold. In other words, the distance values below $L$ tend to be smaller (shorter) than those above 


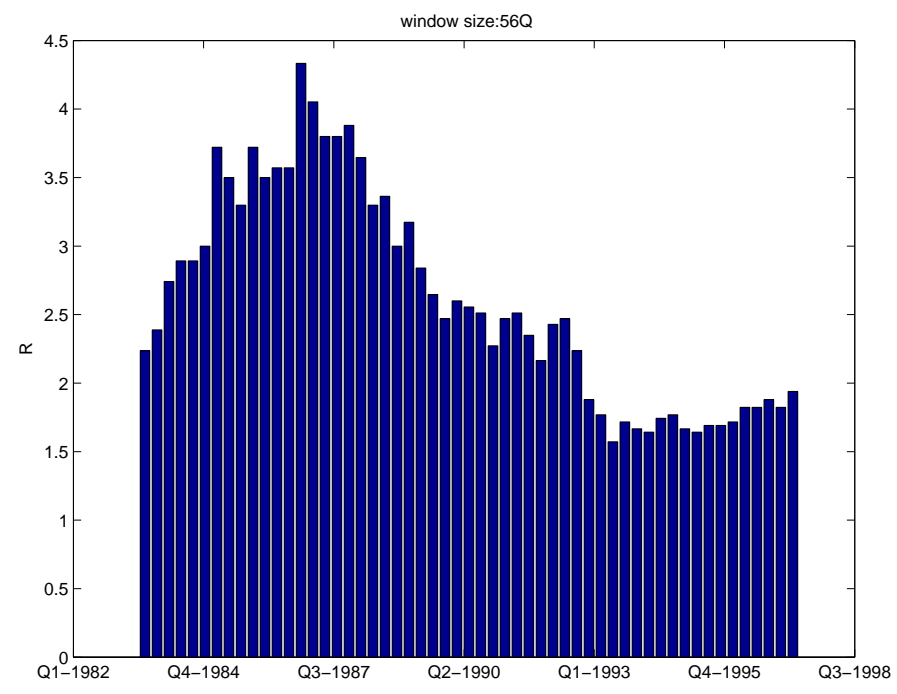

Figure 5: The coefficient R (1983-2011) with a time window of 56 quarters

the threshold, showing that synchronization between countries' positions increases significantly. Moreover, the decrease of $R$ is due to the fact that the networks become less sparse (the number of links increases) after 1997, forcing several residual links to leave this category.

As partially revealed by the increase of $S$, the values of the overall distances decrease after 1997 but there is an increase of the distance between the two lagest clusters, as well a corresponding increase of the value of the endogenous threshold $L$. The results reveal that a major change is occurring in the last period. This difference in the empirically described evolution suggests that in the period of the easy interest rates, the Internet boom and the housing bubble, a new network regime was generated from the cross-border financial linkages.

As Milesi-Ferretti and co-authors point out [25], the last 15 years were characterized by an explosion in the size of cross-border capital flows, measured by the rise of exchanges of claims and liabilities. Consequently, these years have been faced with the emergence of global imbalances and a sharp widening of debtor and creditor positions. The behavior of $R$, while capturing 
the relative strengths of the links above and below an endogenous threshold, helps to characterize the impact of the global crises on the structure of the networks of cross-border capital flows.

In the next section, the classification into debtor and creditor countries improves the empirical characterization of the cross-border and historically dependent networks.

\section{$5 \quad$ Creditor and debtor networks}

Now we are interest in the average position $\bar{p}_{i}$ of each country computed for each of the three periods (1983-2011, 1983-1997, 1997-2011) considered so far. The average position of country $i$ is given by

$$
\bar{p}_{i}=\left\langle C_{i, t}\right\rangle-\left\langle L_{i, t}\right\rangle=\frac{\sum^{t=n}\left(C_{i, t}-L_{i, t}\right)}{n}
$$

where $n$ is the number of time labels. In the case of the three periods under analysis, $n$ is set to 110,55 and 55 respectively.

From this notion of average position - which corresponds to the average net claims of each country - we are able to classify countries as creditor or debtor countries accordingly to the sign of $\bar{p}_{i}$. Table 2 summarizes the average position of each country computed for the three time intervals.

\begin{tabular}{|c|c|c|c|c|c|c|c|}
\hline \hline Country & $83-11$ & $83-97$ & $97-11$ & Country & $83-11$ & $83-97$ & $97-11$ \\
\hline \hline Austria & $\mathrm{C}$ & $\mathrm{D}$ & $\mathrm{C}$ & Italy & $\mathrm{D}$ & $\mathrm{D}$ & $\mathrm{D}$ \\
\hline \hline Bahamas & $\mathrm{D}$ & $\mathrm{D}$ & $\mathrm{D}$ & Japan & $\mathrm{C}$ & $\mathrm{C}$ & $\mathrm{C}$ \\
\hline \hline Bahrain & $\mathrm{C}$ & $\mathrm{C}$ & $\mathrm{C}$ & Luxemburg & $\mathrm{C}$ & $\mathrm{C}$ & $\mathrm{C}$ \\
\hline \hline Belgium & $\mathrm{C}$ & $\mathrm{D}$ & $\mathrm{C}$ & Netherland & $\mathrm{D}$ & $\mathrm{C}$ & $\mathrm{D}$ \\
\hline \hline Canada & $\mathrm{D}$ & $\mathrm{D}$ & $\mathrm{C}$ & Netherland Antilles & $\mathrm{C}$ & $\mathrm{C}$ & $\mathrm{C}$ \\
\hline \hline Cayman Islands & $\mathrm{C}$ & $\mathrm{C}$ & $\mathrm{C}$ & Norway & $\mathrm{D}$ & $\mathrm{D}$ & $\mathrm{D}$ \\
\hline \hline Denmark & $\mathrm{D}$ & $\mathrm{C}$ & $\mathrm{D}$ & Singapore & $\mathrm{D}$ & $\mathrm{C}$ & $\mathrm{D}$ \\
\hline \hline Finland & $\mathrm{D}$ & $\mathrm{D}$ & $\mathrm{D}$ & Spain & $\mathrm{D}$ & $\mathrm{D}$ & $\mathrm{D}$ \\
\hline \hline France & $\mathrm{C}$ & $\mathrm{D}$ & $\mathrm{C}$ & Sweden & $\mathrm{D}$ & $\mathrm{D}$ & $\mathrm{D}$ \\
\hline \hline Germany & $\mathrm{C}$ & $\mathrm{C}$ & $\mathrm{C}$ & Switzerland & $\mathrm{C}$ & $\mathrm{C}$ & $\mathrm{C}$ \\
\hline \hline Hong Kong & $\mathrm{C}$ & $\mathrm{C}$ & $\mathrm{C}$ & United Kingdom & $\mathrm{D}$ & $\mathrm{D}$ & $\mathrm{D}$ \\
\hline \hline Ireland & $\mathrm{D}$ & $\mathrm{D}$ & $\mathrm{D}$ & United States & $\mathrm{D}$ & $\mathrm{D}$ & $\mathrm{D}$ \\
\hline \hline
\end{tabular}


Table 2: Creditor (C) and Debtor (D) countries

Once countries are assigned to their debtor or creditor roles, the dendrograms and corresponding MST networks are presented in Figures 6, 7 and 8. Creditor countries are colored green while debtor ones are colored red.

The observation of these figures gives rise to the following remarks:

1. Debtor and creditor countries occupy (were placed in) separated areas, both in the dendrograms and in the MST networks, showing a clear segmentation of the whole set of countries into two clusters.

2. The average distance value inside each class is significantly smaller than the average network distance.

3. Some networks, as in Figure 6, allows for the observation of both a core group and a peripherical group of countries, whose main role seems to be to tie together small groups of debtor and creditor ones.

4. There is an important increase in the threshold distance value in the last 14 years, since $L_{83-97}=3.94$ and $L_{97-11}=5.52$.

5. There is a corresponding increase in the intercluster distance value in the later period, since it increases from 0.66 (between $\mathrm{DK}(7)$ and $\mathrm{IE}(12)$ ) to 0.86 (between $\mathrm{FI}(8)$ and $\mathrm{CH}(22)$ ).

6. Some countries remain not affected in their relative average position on the network structure, they are: $\mathrm{BS}(2)$ and $\mathrm{CA}(5)$ during the period 1983-2011, $\mathrm{KY}(6)$ and $\mathrm{BH}(3)$ in 1983-1997, and $\mathrm{KY}(6)$ and $\mathrm{AN}(17)$ in the later period. This result seem to be due to the existence of a typical trend in the sign of their net claims. Countries $\mathrm{KY}(6)$ and $\mathrm{AN}(17)$ are both creditors but their performance during the last period is worsening. The same happens with countries $\mathrm{BH}(3)$ and $\mathrm{KY}(6)$ in the period 1983-1997, while the performances of both countries BS(2) and $\mathrm{CA}(3)$ show an improving trend even if these countries occupy a average debtor position along 1983-2011.

When debtor and creditor positions are computed for the shorter time periods (1983-1997 and 1997-2011) an emphasis should be placed on the size 


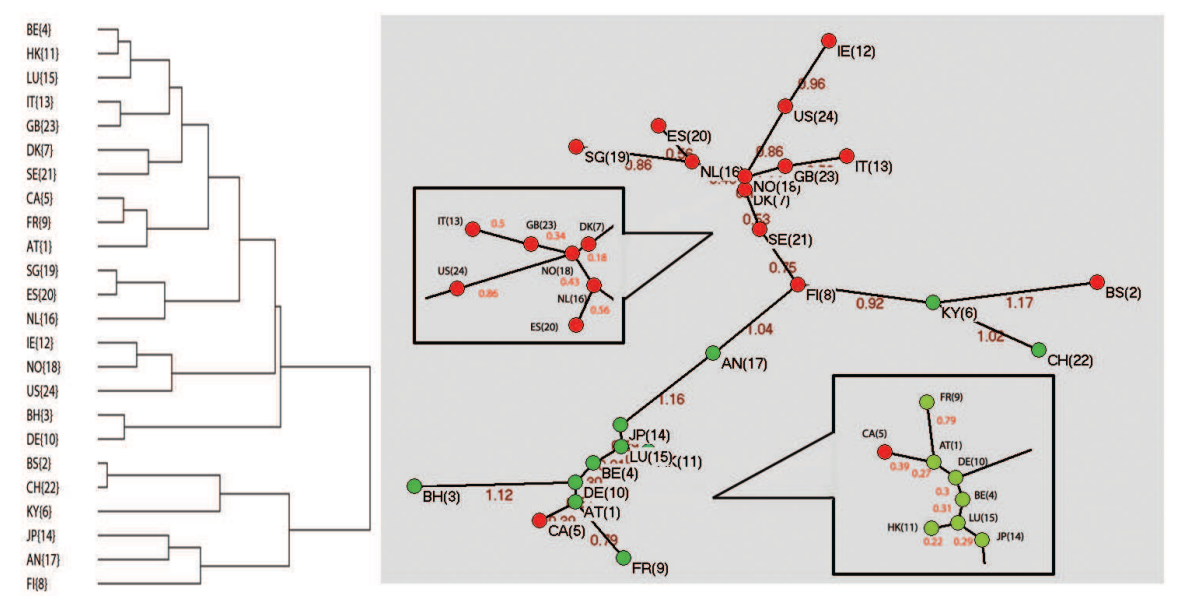

Figure 6: The Dendrogram and the MST Links for the period 1983-2011

of the corresponding debts or credits. To this end, Figures 7,8 present the MST and the dendrogram obtained in each chronological period using large circles to represent both the largest creditors and the largest indebted countries. Results show that:

1. In the first period (Figure 7), eleven countries give rise to a cluster containing the largest indebted countries, which is linked to a second cluster comprising the largest creditor ones.

2. In the second period and accordingly to the dendrogram in Figure 8, the splitting into two separated clusters is less clear. However the network representation of the corresponding MST shows that the network segmentation into creditor and debtor branches remains.

3. In both periods, results show that the three main indebted countries are $\operatorname{IT}(13), \mathrm{GB}(23)$ and $\mathrm{US}(24)$.

4. The branch with the largest creditors is less stable, comprising countries $\mathrm{JP}(14), \mathrm{DE}(10)$ and $\mathrm{CH}(22)$ in the first period and being later comprised of countries $\mathrm{JP}(14), \mathrm{DE}(10)$ and $\mathrm{LU}(15)$. 
In general terms, the first period is characterized by a less pronounced splitting into debtor and creditor countries, being two of heavily indebted countries directly linked to creditor ones. Conversely, after the latest nineties, the heavily creditor countries give rise to a cluster not directly connected to the debtor ones. In what concerns the heavily indebted countries, this last and critical period reinforced their separation from the creditor ones.
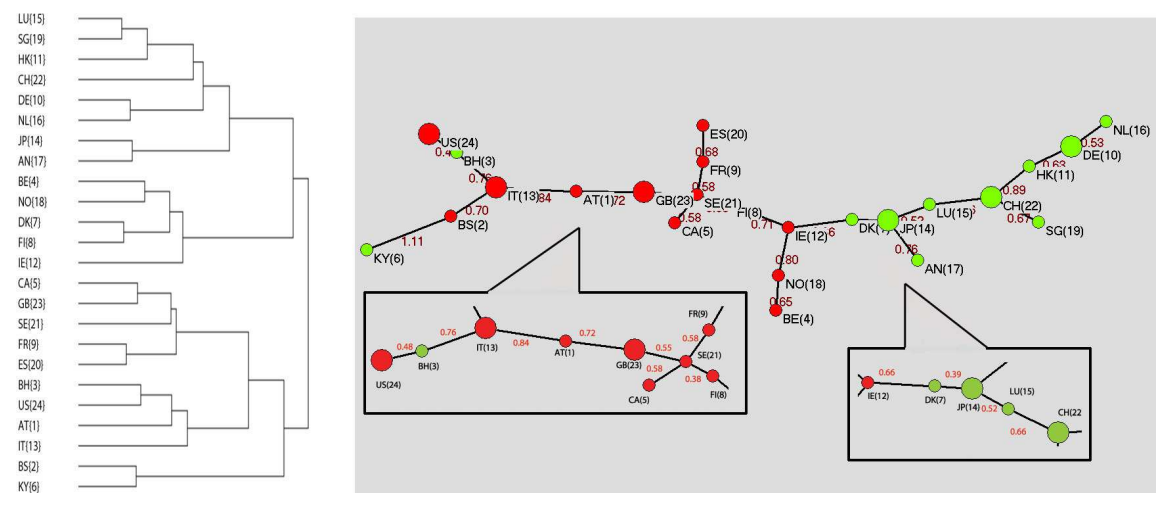

Figure 7: The Dendrogram and the MST Links for the period 1983-1997

\section{Concluding Remarks}

Using time series of interbank liabilities and claims conducted through the international banking system, we have developed complete networks of positions (net claims) between 24 countries. These structures were developed for (i) a 28-years period (1983-2011) and two 14-years periods (ii) (1983-1997) and (iii) (1997-2011).

From the fully-connected representations of (i), (ii) and (iii), the sparse and connected networks of financial linkages across countries were constructed through the Minimal Spanning Tree approach. To reduce the loss of information resulting from the MST construction we have accounted for the number and the intensity of the redundant linkages in each time period. A coefficient of residuality is thus defined to capture the structural changes occurring on the network along the last 28 years. This coefficient highlights an important 


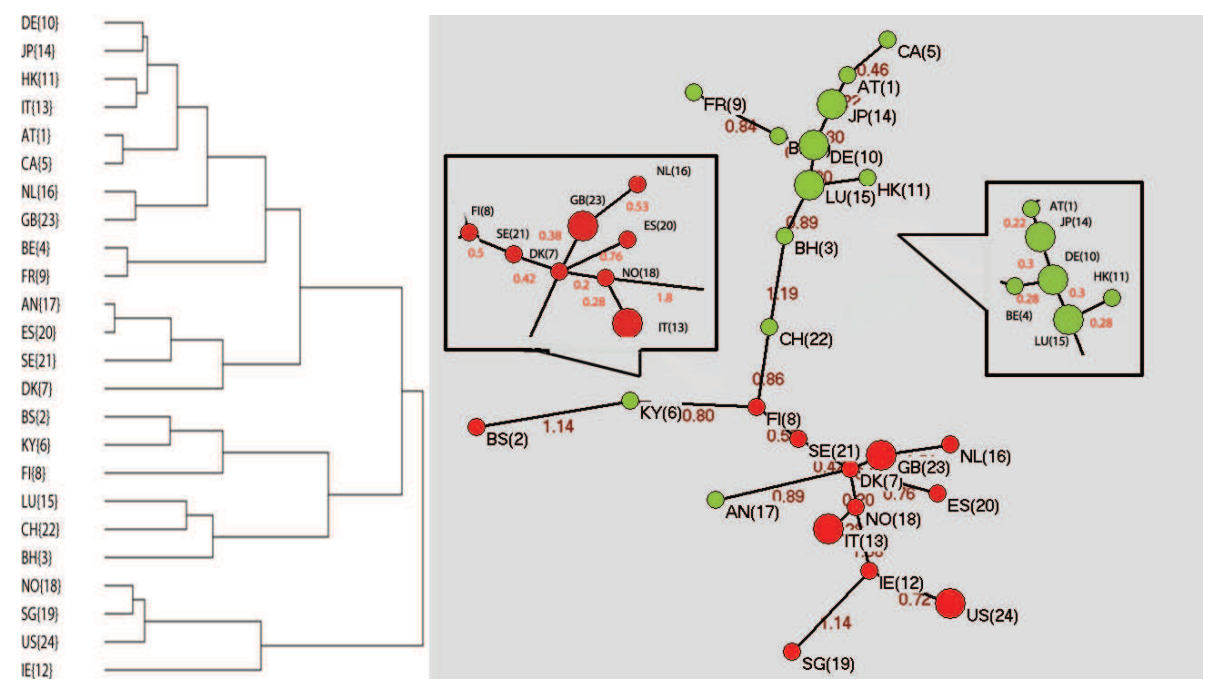

Figure 8: The Dendrogram and the MST Links for the period 1997-2011

modification acting in the financial linkages in the period 1997-2011, and situates the turbulence taking place at the global financial system since the Summer 2007 as replica of a larger structural change going on for a decade.

We have also addressed the role of debtor and creditor countries in the networks obtained from (i), (ii) and (iii) branches of data. Results showed that the period after 1997 is characterized by a stronger splitting of the network into debtor and creditor countries. Such a splitting seems to be even strengthened when emphasis is placed on the size of the corresponding credits and debts.

As the data and the method suggest, this ongoing turbulence is part of a mutation in the structure of the cross-border interdependencies since the latest nineties. Results highlight an important modification acting in the financial linkages across countries in the period 1997-2011, and situate the recent financial crises as replica of a larger structural change going on since 1997.

In future work we envision the application of the same approach to the analysis of networks of liabilities. By placing emphasis on the relative amounts of debts we envision the development of a deeper topological descrip- 
tion of the cross-border financial linkages, still beyond the MST approach.

Acknowledgement: This work has benefited from partial financial support from the Fundação para a Ciência e a Tecnologia-FCT, under the 13 Multi-annual Funding Project of UECE, ISEG, Technical University of Lisbon.

\section{References}

[1] C. Waysand, R. Kevin and J. de Guzman (2010). "European Financial Linkages: A New Look at Imbalances", IMF Working Paper 10/295, Washington: International Monetary Fund.

[2] D. Watts and S. Strogatz (1998). "Collective Dynamics of Small-World Networks", Nature, Vol. 393, 440-442.

[3] M. Jackson and A. Watts (2002). "The Evolution of Social and Economic Networks", Journal of Economic Theory, Vol. 106, 265-295.

[4] E. Helpman and P. Krugman (1985). "Market Structure and Foreign Trade: Increasing Returns, Imperfect Competition and the International Economy", MIT Press, 1985.

[5] E. Nier, J. Yang, T. Yorulmazer, and A. Alentorn (2007), "Network models and financial stability", Journal of Economic Dynamics and Control, Vol. 31, 2033-2060.

[6] F. Allen and D. Gale (1998). "Optimal Financial Crises", Journal of Finance, 1245-1284.

[7] K. Soramaki, M. Bech, J. Arnold, R. Glass and W. Beyeler (2007). "The topology of interbank payment ows", Physica A, Vol. 379, 317-333.

[8] Federal Reserve Board, (2000), Fedwire statistics: Annual Volume and Value. Available at: http://www.Federalreserve.gov/PaymentSystem/FedWire

[9] Y. Fujiwara, H. Aoyama, Y. Ikeda, H. Iyetomi, and W. Souma (2009), "Structure and temporal change of the credit network between banks and large firms in Japan", Economics E-Journal, 2009, 3. 
[10] G. De Masi, G.Iori and G. Caldarelli (2006). "A fitness model for the Italian Interbank Money Market", Phys. Rev. E 74, 66112 .

[11] M. Boss, H. Elsinger, M. Summer and S. Thurner (2004), "An empirical analysis of the network structure of the Austrian interbank market", Oesterreichische Nationalbank Financial Stability Report, June, 77-87.

[12] C. Kubelec and F. Sa (2009), "The Geographical Composition of National External Balance Sheets: 1980-2005", Bank of England and University of Cambridge Working Paper.

[13] R. Garratt, L. Mahadeva and K. Svirydzenka (2011), "Mapping systemic risk in the internationalbanking network", Bank of England Working Paper 413.

[14] P. McGuire, and N. Tarashev (2006), "Tracking International bank flows", BIS Quarterly Review, December, 27-40.

[15] C. Minoiu and J. A. Reyes (2011), "A Network Analysis of Global Banking: 1978-2009", IMF Working Paper No. 74 (Washington: International Monetary Fund).

[16] R. Mantegna, (1999), "Hierarchical Structure in Financial Markets", Eur. Phys. J. B 11, 193-197.

[17] R. Mantegna and H. Stanley (2000), An Introduction to Econophysics: Correlations and Complexity in Finance, Cambridge: Cambridge University Press.

[18] G. Bonanno, G.Caldareli, F.Lillo, S. Miccichè, N. Vandewalle and R. Mantegna (2004), "Networks of Equities in Financial Markets", Eur. Phys J B, 38, 363-371.

[19] J. Dias (2011), "Sovereign debt crisis in the European Union: A minimum spanning tree approach", Physica A: Statistical Mechanics and its Applications, Available online 17 November 2011, ISSN 0378-4371, 10.1016/j.physa.2011.11.004.

[20] P. McGuire and N. Tarashev (2006), "Tracking International bank flows", BIS Quarterly Review, December, 27-40. 
[21] T. Araújo and R. Vilela Mendes (2000), "Function and form in networks of interacting agents", Compl. Syst. 12, 357-378.

[22] R. Vilela Mendes, T. Araújo and F. Louçã (2003), "Reconstructing an Economic Spaces from a Market Metric", Physica A, 32, 635-650.

[23] T. Araújo and F. Louçã (2007). "The Geometry of Crashes - A Measure of the Dynamics of Stock Market Crises", Quantitative Finance, 7(1), 63-74.

[24] T. Araújo and F. Louçã (2008). "The Seismography of Crashes in Financial Markets", Physics Letters A, 372, 429-454.

[25] G.M. Milesi-Ferretti, F. Strobbe and N. Tamirisa (2010), "Bilateral Financial Linkages, Global Imbalances, and International Financial Integration", IMF Working Paper, forthcoming. 